\title{
NO NACIONALISMO GALEGO DE ANTEGUERRA
}

\author{
CARBALLO CALERO AND PRE-CIVIL WAR GALICIAN NATIONALISM
}

\section{Justo Beramendi Universidade de Santiago de Compostela}

\begin{abstract}
Resumo: Descrición da ideoloxía e da acción política de Ricardo Carballo Calero no seo da ala esquerda do nacionalismo galego entre 1926 e 1936: activista universitario, membro da Asociación Nacionalista de Santiago e de Esquerda Galeguista en 1930-1931, redactor do proxecto de Estatuto de Autonomía do Seminario de Estudos Galegos e dirixente do Partido Galeguista en 1931-1936.
\end{abstract}

\begin{abstract}
This is a description of Ricardo Carballo Calero's ideology and his political activity as a left-wing Galician nationalist from 1926 to 1936: as an activist in the University of Santiago de Compostela, member of the Santiago Nationalist Association and the Galicianist Left (1930-1931), co-author of the Home Rule Statute proposed by the Galician Studies Seminar and prominent militant of the Galicianist Party (1931-1936).
\end{abstract}

Palabras chave: Ricardo Carballo Calero, nacionalismo galego, esquerda galeguista, Partido Galeguista, autonomía de Galicia.

Key words: Ricardo Carballo Calero, Galician nationalism, Galicianist Left, Galicianist Party, Galician Home Rule.

Ricardo Carballo Calero (1910-1990) pertence á primeira xeración dos que, en analoxía coa expresión actual nativos dixitais, podemos chamar nativos nacionalistas galegos. Os membros da xeración precedente, a protagonista da transformación do rexionalismo en nacionalismo, chegaron ao galeguismo partindo doutros esquemas ideolóxico-políticos que tiveron que abandonar total ou parcialmente: Antón Villar Ponte dende o republicanismo federal, Lois Porteiro dende o republicanismo rexeneracionista, Johán Vicente Viqueira dende o krausismo, Luís Peña Novo dende o agrarismo socialcatólico, Antón Losada Diéguez 
dende o tradicionalismo filocarlista, Vicente Risco dende un irracionalismo filosófico adobado con exotismos estéticos varios etc. Mesmo os procedentes do vello rexionalismo (os Carré, Lugrís Freire, Banet Fontenla etc), aínda que xa eran galeguistas, necesitaron dar un salto ideolóxico non pequeno para permanecer nunhas Irmandades da Fala nidiamente nacionalistas a partir da Asemblea de Lugo de novembro de 1918. Non é o caso dos mozos que, como Xosé Filgueira Valverde, Ramón Martínez López, Antonio Fraguas, Alexandre Bóveda ou o propio Carballo, ingresaron nos anos vinte nun movemento que tiña xa ben definidos un marco teórico e un programa político que non cambiarían en nada fundamental até despois da Guerra Civil. Eles naceron xa á vida pública como galeguistas no intelectual e nacionalistas no político.

En Carballo Calero isto empezou en 1926, cando chegou a Compostela con dezaseis anos para iniciar os seus estudos de Dereito, procedente de Ferrol, unha cidade na que o nacionalismo organizado se apagara en 1923 logo de contar durante sete anos cunha Irmandade moi activa. As causas desta eclipse, que duraría até 1932, foron, por unha banda, o efecto demoledor da Ditadura de Primo de Rivera (1923-1929) sobre todo o nacionalismo e, pola outra, a baixa dos seus dous líderes maiores, Xaime Quintanilla, que marchou ao PSOE, e Ramón Villar Ponte, que trasladou a súa residencia a Viveiro, onde fundaría outra Irmandade. En cambio, malia as dificultades, o nacionalismo mantiña en Santiago certa presenza dentro e fóra da Universidade. Neste marco, Carballo entrou en relación con algúns compañeiros galeguistas, concretamente con Ramón Martínez López, un dos fundadores do Seminario de Estudos Galegos, que foi o seu introdutor no que quedaba dos círculos nacionalistas. En poucos anos o catecúmeno ferrolán asumiu completo o ideario irmandiño, como demostra a súa actuación a partir de 1928. Vexamos en que consistía ese ideario antes de describir a súa actuación política.

\section{A IDEOLOXÍA}

O sistema ideolóxico-político do nacionalismo galego de anteguerra ${ }^{1}$, como o de calquera outro nacionalismo minimamente desenvolvido, tanto se conta cun Estado propio como se non, ten un elemento central que sustenta o conxunto e é común a todas as súas tendencias: o concepto de nación propia, neste caso Galicia, como suxeito colectivo e lexítimo de soberanía. Os elementos constitutivos desa nación ideal/real, isto é, as características que se aducen para xustificar a súa existencia como nación e os seus dereitos, poden ser diferentes en cada nacionalismo (Beramendi 1999, pp. 171-191). No caso galego, tal concepto ten

1 Para unha análise completa das ideoloxías presentes no nacionalismo galego entre 1916 e 1936, véxase Beramendi 2007, pp. 469-644. 
unha longa xestación de tres cuartos de século, que se inicia nos anos 1840 cos primeiros provincialistas, adquire a súa estrutura básica coa obra de Manuel Murguía entre 1865 e 1891 e chega á súa forma canónica entre 1916 e 1920 cos ideólogos das Irmandades, nomeadamente coa obra de Vicente Risco (1920, 1930), para non cambiar xa significativamente até a década dos sesenta do século XX, cando varias versións do marxismo irrompen con forza no universo galeguista.

Volvendo ao que nos ocupa, para os irmandiños Galicia tiña a condición de nación porque era un pobo descendente dunha rama da familia celta dotado dunha lingua, unha cultura, unha historia e un carácter colectivo singulares e que habitaba unha terra tamén singular; caracteres todos obxectivos, non dependentes da vontade nin da interpretación, que cimentaban polo tanto a obxectividade, antigüidade e indestrutibilidade da nación mesma. E como tal nación, segundo os valores imperantes na política moderna, tiña dereito á soberanía, isto é, a decidir por si mesma e libremente como autogobernarse e como relacionarse con outras nacións, así como a defender a súa identidade nacional, negada e deteriorada pola opresión allea. Até aquí todos de acordo. Por iso non había discrepancias sobre as seguintes cuestións e reivindicacións (presentes todas no programa de Lugo), que eran derivacións directas do anterior:

1ํ) Se Galicia era unha nación, que era España? Había dúas respostas posibles. Primeira: España era outra nación. Neste caso, a única opción estratéxica coherente co nacionalismo galego era a independencia de Galicia, pois non resultaba concibible unha nación dentro doutra. Segunda resposta: España non era unha nación senón un Estado plurinacional no que unha das nacións integrantes, Castela, negaba a identidade e a soberanía das demais (Cataluña, Euskadi, Galicia) e impedía o seu autogoberno mediante o centralismo e o caciquismo. Esta segunda resposta era bivalente respecto da reivindicación principal, pois tan coherente resultaba co nacionalismo a independencia como unha transformación radical do Estado español que permitise o exercicio desas soberanías nacionais. A gran maioría dos irmandiños, se cadra por ser consciente das dificultades case insuperables para formar daquela un Estado galego independente, era partidaria desta segunda vía. De aquí que o seu gran obxectivo político fose:

2a) A substitución do Estado español centralista por unha federación (con matices confederais) das nacións ibéricas, previo exercicio do seu dereito de autodeterminación, e na que debería entrar tamén Portugal. Este federalismo radical inspirábase para a distribución territorial dos poderes no modelo descentralizador establecido por Pi i Margall para a nación española no século XIX, pero diferenciábase del en algo fundamental: agora os suxeitos federables 
non eran os cidadáns españois que construían a súa nación de abaixo a arriba mediante pactos graduados (concello - estado - nación) senón as nacións obxectivas previamente existentes.

$3^{a}$ ) En todo caso, no que atinxe ao poder político, as nacións federadas, entre elas Galicia, conservarían a maior parte da súa soberanía orixinaria ideal, cedendo á federación unicamente o imprescindible para a súa constitución e funcionamento, polo que as únicas competencias federais serían as relacións exteriores, as forzas armadas, os dereitos fundamentais, as comunicacións e conflitos entre as nacións federadas, a moeda e a regulación do funcionamento do mercado.

4ํ) Convencidos de que o clientelismo e o parlamentarismo deturpado da Restauración eran os alicerces maiores da opresión e o atraso de Galicia, avogaban tamén pola democratización radical do sistema: sufraxio universal, dereitos políticos plenos para as mulleres (que non os tiñan), réxime electoral proporcional no canto do maioritario, e erradicación do caciquismo, da fraude electoral e dos políticos profesionais.

5ª) Idénticos obxectivos perseguía a proposta de reforma das administracións públicas, que incluía a supresión das deputacións provinciais ("niños de caciquismo"), a substitución dos concellos rurais polas parroquias, a plena autonomía municipal para os concellos urbanos e un funcionariado autóctono a todos os niveis.

6ª) A preservación e o desenvolvemento da identidade nacional esixía unha galeguización completa da vida pública, isto é, a cooficialidade da lingua galega, a promoción de todas as dimensións da cultura propia, a "soberanía estética da nazón galega" e un sistema político que, alén de democrático, estivese dominado por partidos políticos exclusivamente galegos.

Pero, como acontece con calquera nacionalismo, unha cousa era afirmar a nación e a súa soberanía e outra moi diferente definir como debía ser esa nación por dentro no económico, no social, no político, no moral, no cultural etc. Aquí a unanimidade é imposible nas sociedades modernas, moi heteroxéneas sempre neses eidos. Por iso ningún nacionalismo se basea nunha soa ideoloxía homoxénea, senón que no seu seo conviven un conxunto máis ou menos numeroso de ideoloxías de base unidas polo nexo da asunción da nación común. Esa diversidade pode non traducirse en división partidaria durante un tempo máis ou menos longo, pero tal unidade organizativa adoita desaparecer antes ou despois se hai crecemento sociopolítico sostido nese nacionalismo. 
O nacionalismo galego de anteguerra non era unha excepción niso. Simplificando algo a súa diversidade podemos afirmar que convivían nel dúas tendencias principais ${ }^{2}$. A primeira era unha dereita de mentalidade católico-tradicionalista, nostálxica dun pasado de hexemonía fidalga, que aspiraba a conservar en todo o posible tanto os valores e a moral dos vellos tempos como unha sociedade e unha economía principalmente rurais, sen que por iso negase a necesidade de cambios como a eliminación do foro e a modernización agraria mediante a introdución de novas técnicas e o fomento da comercialización e dun cooperativismo que mellorasen as condicións de vida do campesiñado e minorasen a emigración, programa este no que, por certo, coincidían coa outra tendencia. A segunda tendencia era unha esquerda liberal-democrática, non revolucionaria pero si reformista, aconfesional, máis aberta ao mundo urbano e aos seus problemas e firmemente partidaria dunha auténtica democracia representativa.

A unidade organizativa resistiu as tensións entre uns e outros durante os seis primeiros anos de vida das Irmandades da Fala, pero finalmente crebou en 1922, aínda que esta ruptura seguiu estritamente as divisorias ideolóxicas que, porén, si estaban no fondo. Perante as oportunidades que ofrecía a nacente República, a unidade recupérase en 1931 co Partido Galeguista pero sobre as mesmas areas movedizas da confrontación ideolóxica interna que outra volta acabará desembocando en escisións en 1935 e 1936. En todo caso, no momento que aquí nos interesa, o período 1926-1930, eses enfrontamentos perderan transitoriamente gran parte do seu sentido porque a Ditadura de Primo de Rivera condenara as Irmandades á inoperancia política e a refuxiarse na elaboración teórica e nunha moi fecunda produción literaria e cultural. É o momento do nacemento do Carballo Calero nacionalista. Pero que tipo de nacionalista? Pois un nacionalista de esquerdas, como demostran sen lugar a dúbidas os seus pronunciamentos e a súa traxectoria política dos anos posteriores. Vexámolo.

\section{A ACTIVIDADE POLÍTICA}

O réxime militar nado do golpe de Estado encabezado o 13 de setembro de 1923 polo xeneral Miguel Primo de Rivera provocara a desorganización case total das Irmandades. Só permaneceu en pé, aínda que moi diminuída, a da Coruña, que continuou publicando A Nosa Terra, por suposto sometida á censura. En Santiago,

2 Había tamén gromos moi embrionarios de nacionalistas socializantes sen incidencia apreciable na marcha do conxunto. Nuns casos, como o do ferrolán Xaime Quintanilla, acaban marchando ao PSOE nos anos vinte. Noutros, xa nos anos trinta, ora actúan dentro do sector demócrata, como Ramón Suárez Picallo, ora montan unha minúscula organización propia, como a Unión Socialista Gallega de Xan Xesús González. 
se ben deixara de funcionar a delegación compostelá da Irmandade Nazonalista Galega, froito da escisión de 1922, o nacionalismo perduraba baixo a superficie refuxiado no acubillo cultural do Seminario de Estudos Galegos, escola de formación de Carballo e doutros compañeiros de xeración. O Carballo mozo iniciou cedo a súa andaina de activista universitario entrando na Asociación Profesional de Alumnos da Facultade de Dereito e na sección galega da estatal Federación Universitaria Escolar (FUE), nas que non tardaría moito en acceder a postos dirixentes.

A finais de 1928, só dous anos despois da súa chegada a Compostela e con dezaoito de idade, o seu compromiso co nacionalismo era xa forte abondo como para superar o desánimo da maioría dos seus compañeiros galeguistas e participar no reducido grupo que intentou, sen éxito, reorganizar as Irmandades na clandestinidade, nunha reunión, probablemente na casa de Camilo Díaz na rúa das Hortas de Santiago, á que asistiron Federico Zamora en representación da IF da Coruña, Vicente Risco, Florentino L. Cuevillas e Ramón Otero polo grupo de Ourense, e Paulino Pedret, Camilo Díaz, Antonio Fraguas e Ramón Martínez López polo de Santiago ${ }^{3}$. Acordaron alí fundar "unha organización nacionalista pura, sin parlamentarismos, nin regramentos, o máis segreda, rápida e eficaz posibre", da que Otero foi elixido provisoriamente "cabezaleiro supremo". Aínda que esta organización non callou, a tentativa demostra a vontade de manter vivo o nacionalismo organizado, pese ás dificultades case insuperables do momento.

En xaneiro de 1930, o ditador, fracasado o seu intento de institucionalizar un sistema autoritario de partido único (a Unión Patriótica) e perdidos case todos os apoios, incluídos o da Monarquía e os de boa parte do Exército, dimitiu e foi substituído á cabeza da ditadura por outro xeneral, Dámaso Berenguer. Neste breve período de tránsito á República, que pasou á historia co significativo nome de "Ditabranda", houbo unha maior tolerancia do poder coas liberdades de expresión e coa reunión das forzas políticas; algo que aproveitaron todas as forzas prodemocracia para reactivárense. Tamén os universitarios.

En Compostela, vemos a Carballo Calero reclamando máis galeguismo aos seus compañeiros (Carballo 1930a) ${ }^{4}$. Repróchalles o seu mimetismo respecto de todo o que vén de Madrid, mesmo na súa loita pola democracia, como esa admiración por Unamuno, un españolista que, na súa opinión, debía ser inaceptable para os galegos. En outubro de 1930 fala en nome de todos os "escolares" na solemne inauguración do curso 1930-1931, feito que demostra que era xa un dos principais

3 Coñecemos esta reunión e os seus resultados por unha carta de Otero Pedrayo a Losada Diéguez, datada en Ourense o 3 de marzo de 1929, que puiden consultar entre os papeis do segundo no Pazo de Moldes.

4 "esta groria dos estudantes galegos ten un caráiter «importado» que non podo me acustumar a ollalo como algo verdadeiramente xurdio. Pois é mester dicilo: falla nos estudantes de Compostela un esprito galego" (1987, p. 101). 
líderes dos universitarios. Nesa condición encabeza en xaneiro de 1931, como el mesmo nos conta (Carballo 1931), o enfrontamento dos estudantes co alcalde e exrexionalista Felipe Gil Casares.

No referido discurso (Carballo 1930b) exprésase como dirixente corporativo avogando por unha organización dos estudantes "para fines profesionales, porque sólo la profesionalidad es aglutinante capaz de unirlos a todos" (1987, p. 92), aínda que respectando sempre a ideoloxía de cadaquén. E rexeita as agrupacións políticas na Universidade porque na súa opinión serían nocivas para a institución e para os estudantes en canto estudantes. Con todo, ao final non pode, ou non quere, evitar colarlle ao seu académico auditorio, maioritariamente españolista, unha arenga claramente galeguista reivindicando que:

la Universidad gallega lo sea de cuerpo entero. En esta hora jubilosa en que parece que los pueblos que integran el Estado español acusan con más relieve que nunca su afán de personalidad y su ansia de vida propia, la clase escolar gallega auténtica cree cumplir un deber ineludible solicitando por mi boca la galleguización de su Universidad. Galicia existe; y por existir tiene derecho a una cultura propia: y para ello es preciso que tenga un propio centro de cultura. Aspiramos a crear una vida universitaria auténticamente gallega; aspiramos a obtener un espíritu gallego en las aulas de la Universidad. El primer paso hacia esos ideales es lograr que en nuestras cátedras coexista oficialmente con el castellano, nuestra lengua vernácula (1987, pp. 93-94).

Asemade traballa tamén por reactivar o nacionalismo fóra da Universidade participando no movemento de reorganización que tiña lugar en toda Galicia. Algo non doado, non só polas limitacións que impoñía a todos a ditadura, por moi "branda" que se manifestase agora, senón tamén por certos feitos acontecidos no seo do galeguismo, concretamente na Coruña. A Irmandade desta cidade fora sempre a máis numerosa, activa e organizada con moito. De feito, agrupara tantos ou máis afiliados que todas as demais xuntas. E nela predominara sempre a tendencia democrática e filorepublicana. Como dixen, o seu enfrontamento co sector católico-tradicionalista provocara en 1922 a escisión. E aínda que a desgraza común suavizara algo a ruptura durante a Ditadura, a gran maioría dos irmandiños coruñeses foi perdendo a fe na viabilidade dunha acción política expresamente nacionalista e acentuando a súa proclividade de sempre a unha alianza cos republicanos. Tanto que case todos eles, encabezados nada menos que por Antón Villar Ponte, converxeron en setembro de 1929 co grupo republicano de Santiago Casares Quiroga para formar a Organización Republicana Gallega Autónoma 
(ORGA), partido autonomista pero non nacionalista. E procuraron convencer o resto de "irmáns" de Galicia de que seguisen o seu exemplo.

Pero non o conseguiron. Logo dun fracasado intento de reunificación na VI Asemblea Nacionalista (A Coruña, 26-27 de abril de 1930), os que cofundaran a ORGA seguiron de momento nela, aínda que a maioría retornaría ao rego nacionalista cando Casares Quiroga, xa na República, demostrase o tépedo do seu autonomismo ao tempo que o nacionalismo emprendese unha traxectoria ascendente. E os que non estaban dispostos a renunciar ao nacionalismo, a maioría dos de fóra da Coruña, iniciaron un proceso de reorganización fragmentada por localidades, que acadou especial intensidade nas provincias de Pontevedra e Ourense pero que se deixou sentir tamén fóra destas en diferentes cidades e vilas ${ }^{5}$. Unha delas, Compostela.

Carballo Calero foi dos que ficaron no nacionalismo en todo momento. Así que en 1930 contribuíu a fundar a Asociación Nacionalista de Santiago (ANS), nome moi diferente do da vella Irmandade e que parece pensado para marcar distancias cos que marcharan á ORGA. Entre os 34 membros da ANS que teño censados había de todo ${ }^{6}$. Presidida polo canteiro e despois avogado Xan Xesús González, líder nos anos trinta do minoritario sector socialista do nacionalismo, agrupaba todas as tendencias ideolóxicas, así como veteranos e novos adeptos. Na dereita situábanse o vello Manuel Banet Fontenla, que trasladara a súa notaría dende Monforte, e os seus dous fillos, tamén notarios, xunto cos sacerdotes Xosé M. Cabada, Manuel García, Xesús Carro e Paulino Pedret, así como a catedrática M. a Pura Lorenzana, o mestre Xosé Mosquera, o empregado Manuel Beiras, o deseñador Camilo Díaz, o avogado Francisco Vázquez e o empresario e presidente do Círculo Mercantil de Santiago, Santiago de la Riva Barba. No centroesquerda ou na esquerda, os estudantes Ricardo Carballo Calero, Álvaro Cunqueiro, Francisco Fernández del Riego, Sebastián González García-Paz, Luís Seoane, Lois Tobío, o pintor Mariano Fernández Granell, o músico Ángel Brage e o propio presidente da Asociación, Xan Xesús González.

No ano seguinte Carballo participou tamén na fundación doutra organización, Esquerda Galeguista, esta de ámbito galego e máis homoxénea ideoloxicamente, como o seu mesmo nome indica. Facían parte dela algúns membros da ANS (Car-

5 Rexurdiron, con un ou outro nome, a maioría das Irmandades preexistentes, como as de Ourense, Santiago, Pontevedra, Monforte, Vilalba ou Vilagarcía. Non así a de Ferrol, de momento. E naceron outras onde antes non as había, como en Noia, ou foran insignificantes, como en Vigo, que agora contaba co Grupo Autonomista Galego dirixido por Valentín Paz-Andrade.

6 A composición socioprofesional era a seguinte: dez estudantes universitarios, a maioría de dereito e letras; catro profesores ou mestres; catro sacerdotes; tres notarios; tres empregados; tres artistas/músicos; dous empresarios; dous avogados; dous comerciantes e un médico. Todos eles homes, menos unha muller, a catedrática de Instituto María Pura Lorenzana. 
ballo Calero, Lois Tobío, Luís Seoane, Antonio Fraguas), xunto con outros que non o eran, como Ánxel Casal (retornado dende a ORGA), Álvaro de las Casas (catedrático en Noia), Arturo Cuadrado ou Xosé Eiroa. Este grupo, do que só coñezo 25 membros, tivo escasa actividade política, fóra de publicar algún manifesto. De postulados moi radicais, chamou a absterse nas eleccións a Cortes Constituíntes de 28 de xuño de 1931 porque desconfiaba da pureza democrática e da vontade descentralizadora da nacente República?

Fóra destas reticencias marxinais, o certo é que a partir do 14 de abril o conxunto do nacionalismo galego se puxo claramente do lado da República. A súa ala dereita, coa esperanza de que fose federal e polo tanto permitise o nacemento do Estado galego que todos reivindicaban; e a ala esquerda polo mesmo motivo e ademais porque traía a democracia. A Nosa Terra, voceiro común, saudaba no seu editorial de $1^{\text {o }}$ de maio a República coa "mais íntima satisfaición". Mais por se acaso, todos intensificaron, Carballo incluído, a súa campaña proautogoberno de Galicia. E así, o 26 de abril, co gallo da conmemoración dos fusilamentos de Carral de 1846, Otero Pedrayo, Castelao e Paz-Andrade protagonizaron pola mañá un mitin en Ourense, que repetiron pola tarde en Vigo, co reforzo de Carballo Calero (na súa condición de expresidente da FUE galega), no Teatro García Barbón. Todos reclamaron con firmeza unha República Federal e que Galicia fose tratada igual que Cataluña e Vasconia na nova Constitución ${ }^{8}$. O domingo seguinte, 3 de maio, celebráronse actos semellantes en Pontevedra, A Estrada e Cambados, xa sen a escusa dos mártires de Carral.

Pero non todo foron mitins. O 4 de xuño, só mes e medio despois da proclamación da República e tres semanas antes das eleccións a Cortes Constituíntes, o sector exirmandiño que aínda permanecía na ORGA, encabezado por Antón Villar Ponte e Luís Peña Novo, aproveitou que Santiago Casares Quiroga andaba en Madrid moi ocupado no goberno provisional para celebrar na Coruña unha asemblea proestatuto á que foron convocadas todas as forzas políticas e entidades interesadas. Naturalmente os nacionalistas, malia estaren fragmentados aínda en numerosos grupos, non faltaron á cita. E Carballo Calero tivo unha participación de peso na iniciativa, pois foi o encargado de redactar, xunto con Lois Tobío, o anteproxecto de Estatuto que o SEG presentou a esa asemblea e ao que Alexandre Bóveda engadiría a coñecida addenda sobre a cuestión fiscal e financeira (SEG 1931a, 1931b). O texto, non moi diferente no grao de autogoberno das Bases que achegaron os da ORGA, pero moito máis desenvolvido, partía tamén da premisa

7 "Temos a obriga de confesar que o problema galego vaise tornando pra nós incompatibre cos homes da Hespaña”. O manifesto, datado en Santiago o 14 de xuño de 1931 (A Nosa Terra, 285, 1/VII/1931), reivindicaba como propio o proxecto de Estatuto aprobado na Asemblea de 4 de xuño na Coruña.

8 Véxase El Pueblo Gallego, 25 e 28/IV/1931. 
desa República federal que finalmente non foi, polo que establecía un nivel de soberanía e de regaleguización para a Galicia federada ("Estado libre drento da República Federal Española", segundo o art. 1ํ) moi por riba das limitadas competencias que permitiría despois a Constitución republicana para as "rexións autónomas". Pero o texto incluía tamén cláusulas socioeconómicas que indicaban moi claramente o encadramento de Carballo, Bóveda e Tobío na tendencia máis democrática e socialmente avanzada do nacionalismo. Tal é, por exemplo, un sistema fiscal progresivo, imprescindible para financiar algunhas políticas como o fomento das cooperativas ou a banca pública ${ }^{10}$. Daquela a fiscalidade (socialmente moi inxusta) gravitaba sobre os impostos indirectos e secundariamente sobre os bens raíces, así que as propostas deste tipo en materia facendaria eran case revolucionarias. Na mesma liña, hai tamén elevadas declaracións de principios absolutamente impracticables nunha economía real de mercado que, con máis ou menos matices, todos eles asumían. Aínda que son moi ilustrativas da súa arela de fondas reformas sociais ${ }^{11}$.

Como ben sabemos, nas eleccións de 1931 o nacionalismo galego conseguiu, por primeira vez na súa historia, representación no Congreso dos Deputados: Alfonso R. Castelao, coa Candidatura Galeguista de Pontevedra que loitaba en solitario; Ramón Otero Pedrayo, co Partido Nazonalista Repubricán de Ourense, que se presentaba en coalición; e Antón Villar Ponte e Ramón Suárez Picallo nas listas da ORGA pola Coruña. Catro voces a loitar dende Galicia pola República Federal. Tamén sabemos que nesas Cortes os partidarios dese tipo de república resultaron minoría, porque nin a maioría dos diversos republicanos nin os socialistas, que formaban o binomio maioritario e gobernante, estaban polo labor. Así que ao cabo o modelo resultante, o chamado Estado Integral, só consideraba unha moi moderada descentralización para aqueles territorios que conseguisen constituírse en "rexión autónoma" logo de superar uns requisitos realmente duros ${ }^{12}$. Esta autonomía light estaba moi por debaixo das aspiracións dos nosos nacionalistas, pero estes, conscientes das súas escasas forzas, aceptaron o mal menor e comprenderon

9 Para máis detalles das diferentes propostas presentadas a esa asemblea, incluída a so SEG, véxase Beramendi (2007, pp. 811-818) e tamén Vilas (1975).

10 "Art. 34. Exisitirá un imposto directo único que gravará as rendas, cun gravamen maor para as rendas que proveñan do capital que pra as que procedan do traballo, i-eximindo d'imposto as rendas do traballo menores da cantidade que a lei corespondente determiñe. Art. 35. Haberá ademais os impostos indireitos que se establezan con arreglo âs leises".

11 "Art. 30-b) garantizar o traballo a todol-os cibdadáns, segundo as suas condizóns e as suas necesidades, con arreglo as eisixencias da xustiza social; c) regular a propiedade rural de xeito que veña ficar ceibe de toda cárrega pra o que a traballa; d) proporcionar a todol-os cibdadáns os meios necesarios pra o seu preno desenrolo espritual".

12 Pódese atopar unha análise da descentralización no Estado Integral da II República en Beramendi (2007 pp. 774-785). 
que conseguilo non era doado, polo que debían dotarse dun instrumento político forte e eficaz. Por iso neses meses acabaron converxendo todos na reunificación, pero non para repetir a experiencia das Irmandades, senón para crear un partido moderno con criterios organizativos moi diferentes dos da etapa da preditadura.

Para conseguilo aparcaron (que non enterraron) as diferenzas ideolóxicas e, reunidos en Pontevedra o 5 e 6 de decembro de 1931, fundaron o Partido Galeguista. As crónicas recollen a presenza de Carballo neste acto fundacional pero ningunha intervención súa nos debates. Mais o feito de que fose elixido para o Consello Executivo ${ }^{13}$, con só vinte e un anos, revela que xa era un nome importante. A composición deste primeiro órgano de dirección era integradora en todos os sentidos, pois procuraba o triplo equilibrio xeracional, territorial e ideolóxico, equilibrio que desaparecería dous anos despois en beneficio da ala esquerda. Carballo sería reelixido para outro mandato na II Asemblea do PG, cuxo regulamento redactaría el mesmo (PG 1932).

Pero este protagonismo experimenta despois unha eclipse duns dous anos, que comeza coincidindo coa súa marcha de Compostela a Ferrol en 1932, unha vez rematados os estudos de dereito, para preparar os exames de acceso a unha praza de funcionario no concello. $O$ feito é que neses dous anos apenas aparece nas fontes. É probable que, afastado dos grandes centros de actividade do galeguismo nese momento e ocupado en iniciar a súa carreira profesional, dedicase todas as súas enerxías políticas á resurrección do nacionalismo ferrolán creando a agrupación local do partido, que chegaría a presidir en 1936. Segundo as miñas pescudas, este grupo chegou a contar con 31 afiliados $^{14}$.

Porén, tamén deixou algunha pegada da súa actividade fóra da vida orgánica do partido. Unha, no proceso autonómico. Reactivado a mediados de 1932 dende o Concello de Santiago, Carballo presentou o 10 de setembro de 1932 unha emenda ao anteproxecto de Estatuto de Autonomía sometido a información pública para que os conselleiros fosen nomeados e cesados polo presidente do Consello de Goberno e non polo presidente de Galicia. A emenda foi incorporada pola comisión redactora ao texto que finalmente aprobaría a Asemblea de Municipios, celebrada en decembro en Santiago (Cores 1998, pp. 230-232 e 348-349).

Outra, no movemento universitario. O seu nome encabezaba as 25 sinaturas de estudantes ao pé do manifesto que en marzo de 1933 expoñía a política do PG

13 Xunto con Pedro Basanta, Lois Tobío, Álvaro de las Casas, Xosé Núñez Búa, Ramón Martínez López, Víctor Casas, Manuel Lugrís Freire, Plácido R. Castro, Vicente Risco, Manuel Banet Fontenla, Valentín Paz-Andrade, Antonio Alonso Ríos, Alexandre Bóveda e Xosé Filgueira Valverde. Os deputados Alfonso R. Castelao e Ramón Otero Pedrayo tiñan voz pero non voto no Consello porque así o establecía o estatuto do partido.

14 Entre os que había oito empregados, catro comerciantes, catro obreiros, dous estudantes, dous profesores, un arquitecto, un viaxante de comercio, un mariñeiro, un chofer e un practicante. 
para a universidade galega (PG 1933). Logo de avogaren por unha universidade menos funcionarial, máis científica e flexible, que se preocupase pola resolución dos problemas de Galicia e resultase accesible á mocidade de menos recursos - de modo que o estudo superior fose un dereito de todos e non un privilexio- e de apoiar algunhas iniciativas modernizadoras como a prevista Residencia (xermolo do actual campus sur de Santiago), resumían as súas arelas en cinco puntos:

1. Autonomía de Galicia.

2. Independencia universitaria con relación a Madrid.

3. Federación Oficial Escolar Universitaria única e galega.

4. Igualdade de dereitos para o galego en relación ao castelán.

5. Establecemento de cátedras permanentes de cultura galega.

Todo cambiou en novembro de 1933 coa vitoria das dereitas españolas nas eleccións xerais. O PG competira en solitario e, malia obter un número de votos moi aceptable en toda Galicia (quedou por diante do PSOE nas provincias da Coruña e Pontevedra), perdeu todos os seus deputados. Pero non foi esa a perda maior. Os gobernos do chamado Bienio Negro, como non podía ser doutro modo nas dereitas españolas daquel tempo, esquecendo a Constitución, practicaron dende o principio unha política centralista acosando a única autonomía xa en vigor, a de Cataluña, e metendo no conxelador os demais Estatutos en tramitación, empezando polo galego, ao que só lle restaba o referendo popular mediante un plebiscito que debía convocar o goberno central. Até ese momento o PG procurara manterse no centro do espectro político para salvagardar os seus equilibrios internos, pero agora a situación política deixaba algo moi claro, algo que a dirección do partido entendeu axiña: a autonomía de Galicia pasaba por unha fronte común do nacionalismo e as esquerdas, ou parte delas, que cambiase o signo político do poder central.

Esta perspectiva, unha vez formulada, avivou no seo do PG o vello preito dos anos vinte entre os neotradicionalistas, opostos agora ao carácter laico da República e sempre a calquera alianza cos partidos republicanos, e os demócratas, dispostos a que a consecución da autonomía prevalecese sobre a paz interna. Este dilema foi o centro dos debates na III Asemblea do PG (Ourense, 13-14 de xaneiro de 1934) que, malia a táctica illacionista defendida daquela por Vicente Risco e Iglesia Alvariño, apoiou finalmente as teses de Suárez Picallo e Víctor Casas e aprobou a colaboración cos partidos de esquerda para avanzar cara á "autodetermiñación" e á "republicanización"15.

15 Véxase a extensa crónica desta asemblea en A Nosa Terra, 321 (28/I/1934). 
Carballo non estivo presente pero axiña fixo pública a súa postura mediante un artigo cun título expresivo abondo, "Xa somos ezquerda" (Carballo 1934a), no que non esquivaba a posibilidade de que o enfrontamento acabase nunha escisión do partido, pero, sempre racional, a negaba porque, segundo el, a fraqueza numérica do PG "escorrenta toda probabilidade racional de coidar na división". Recoñecía que a polarización da sociedade en Galicia e en España era unha realidade ineludible. "E por imperativo vidal hay que tomar posición n-un ou n-outro bando" e "o Partido Galeguista non pode dubidar: ténse que situar da banda da ezquerda" porque "da dereita nada pode agardar Galicia". Ademais, "somos xa ezquerda, porque os galeguistas cristiáns tiveron sempre unha amplia visión dos problemas cuias solucións programáticas definen o ezquerdismo". En calquera caso, o esencial era "salvar a nosa obra de perecer no berce dourado de un idealismo baleiro", en alusión benévola a Risco e compañía.

Como era de esperar, as decisións da Asemblea non trouxeron a paz. Despois do fracasado alzamento das esquerdas en outubro dese mesmo ano, que pasou á historia como "a revolución de Asturias", o goberno non só reprimiu con dureza os responsables senón que aproveitou a ocasión para castigar toda a oposición. En Galicia intentou descabezar o PG, que nada tivera que ver coa sublevación, desterrando a Castelao, secretario político, a Badajoz e a Alexandre Bóveda, secretario xeral, a Cádiz. O resultado foi contraproducente, como adoita acontecer nestes casos. A dirección do partido viu neste ataque inxustificado un motivo máis para acelerar a viraxe emprendida e negociou en pouco tempo unha alianza coa Izquierda Republicana de Manuel Azaña, partido resultante da recente unión da Acción Republicana co Partido Republicano Gallego (antiga ORGA) de Casares Quiroga e outros grupos republicanos menores. E naturalmente este pacto alporizou aínda máis á dereita galeguista.

Coas tensións internas ao tope celebrouse a IV Asemblea (Santiago, 20-21 de abril de 1935). Poucos días antes, Carballo (1935b) publicara un artigo no que, ademais de gabar o autonomismo de Azaña, criticaba con dureza a dereita do partido dicindo que os contrarios á alianza cos republicanos vivían "no limbo" porque non coidaba "que teñamos fundado o Partido pra esmorecer contemprando o umbigo de Galicia”.

Desta vez si asistiu, e en lugar destacado, pois ocupou unha das vicepresidencias da Mesa da Asemblea, presidida por Xosé Núñez Búa. No debate e votación da memoria da secretaría política, lida por Sebastián González en ausencia de Castelao, foi el quen falou en nome de todos os que presentaran mocións de apoio ás xestións da dirección. Fronte á minoría, encabezada desta vez por Otero Pedrayo, que insistía en que o PG competise en solitario, Carballo argumentou que, dada a realidade da situación política, se o galeguismo quería conseguir a autonomía, 
non tiña máis remedio que aliarse coas esquerdas españolas. Despois dunha longa discusión, a asemblea ratificou finalmente esa alianza por unha ampla maioría.

Ás sete da tarde, nun pavillón da Ferradura "ateigado de xente", tivo lugar o acto público de clausura, presidido por Ricardo Carballo Calero, con discursos deste e de Antón Villar Ponte, Xerardo Álvarez Gallego e Ramón Suárez Picallo, nos que se adiantaron os contidos do manifesto (PG 1935) que se publicaría no número seguinte d'A Nosa Terra e tamén como folla independente. $\mathrm{O}$ texto, fóra dalgunha pirueta retórica para intentar calmar a disidencia interna e de denunciar as "agresións á nosa economía" cos conseguintes problemas para labregos, mariñeiros e obreiros, definía sen lugar a equívocos o novo lugar do PG no escenario político: rexeitamento das políticas do goberno dereitista, "intanxibilidade, aínda cos seus erros, da Constitución de 1931” e adhesión á liña política feita pública o 12 de abril por Izquierda Republicana e os seus socios. A mensaxe á opinión pública estaba moi clara: o nacionalismo galego incorporábase á fronte común de centroesquerda a prol da restauración da democracia republicana, autonomía incluída. Este foi sen dúbida un dos momentos de maior protagonismo público de Carballo Calero. Pero non sería o único.

Nos meses seguintes, o PG, en cumprimento dos acordos adoptados, asinou un pacto con Izquierda Republicana e da súa man entrou en xaneiro de 1936 na Fronte Popular en Galicia. O funcionamento interno, radicalmente democrático, do PG esixía que todo isto fose aprobado directamente polas bases, e con tal fin convocouse unha asemblea extraordinaria para o 25 de xaneiro de 1936 en Santiago. Carballo, en claro ascenso dentro do partido, foi elixido presidente da Mesa. Ratificada por aclamación a entrada na Fronte Popular, procedeuse a elixir as persoas que ocuparían os postos que se reservasen ao PG nas listas da coalición, que aínda se estaban negociando. Aínda que previsiblemente serían só catro ou cinco postos, votáronse 27 nomes. Carballo quedou en oitava posición con 1416 $\operatorname{votos}^{16}$. E na súa condición de presidente da Mesa pechou a asemblea cun discurso que mereceu este comentario do cronista: "As súas verbas son tan fermosas i-emocionadas que nos parece escoitar a un Otero Pedrayo mozo e pausado"17.

Coa vitoria da Fronte Popular o PG volveu ter deputados en Madrid: Castelao, Suárez Picallo, Alonso Ríos e Antón Villar Ponte (que morrería en marzo). No que atinxe a Carballo, as secuelas desa vitoria déronlle tamén oportunidade de contribuír nada menos que á elección de Manuel Azaña como presidente da

16 O máis votado foi Castelao, con 1785 votos, seguido de Suárez Picallo (1775), Antón Villar Ponte (1771) e Alexandre Bóveda (1735). Detrás de Carballo aparecían persoeiros de moito peso no nacionalismo, e non só aqueles que se afastaran da liña do partido, como Otero Pedrayo ou Paz-Andrade, senón tamén outros da ala esquerda, como Víctor Casas ou Ánxel Casal.

17 A Nosa Terra, 403 (31/I/1936), p. 3. 
República, pois nos comicios indirectos de 26 de abril, para substituír o anterior presidente, foi un dos compromisarios electos nas listas da Fronte Popular. Nesa condición asistiu tamén en Madrid á reunión - na que actuou de secretario- preparatoria da convocatoria do referendo do Estatuto de Autonomía, último paso do proceso estatutario que permanecía bloqueado dende a súa aprobación pola Asemblea de Municipios de decembro de 1932. E foi, como todos os nacionalistas, un activo participante na campaña previa a aquel 28 de xuño, na que o texto ficou ratificado directamente polo electorado do país.

Esta alegría durou pouco, exactamente vinte días. Carballo tivo a "sorte" de atoparse o fatídico 18 de xullo en Madrid, a onde fora para preparar as oposicións a profesor de ensino medio, logo de rematar por libre a licenciatura de Filosofía e Letras. A xulgar polo acontecido nos meses seguintes con moitos compañeiros seus en Galicia, esta circunstancia moi probablemente lle salvou a vida. Pero pechou brutalmente unha xuventude de ilusionado compromiso e abriu o período máis penoso da súa vida. Combatente no exército republicano, derrotado e prisioneiro en 1939, xulgado e condenado a prisión, inhabilitado despois durante moitos anos para o exercicio da función pública, custoulle outros moitos recuperar a plenitude dos seus dereitos cidadáns e profesionais. Pero en ningún momento abxurou das súas conviccións nacionalistas para aliviar a súa situación.

\section{REFERENCIAS BIBLIOGRÁFICAS}

Beramendi, Justo (1999). La Historia política: algunos conceptos básicos. [Santiago de Compostela]: Tórculo Edicións.

Beramendi, Justo (2002). Carballo Calero, un xove nacionalista, 1926-1936. En: Teresa López e Francisco Salinas, eds. Actas do Simposio Ricardo Carballo Calero. Memoria do século. A Coruña: Universidade da Coruña / A.S.P.G., 281-294.

Beramendi, Justo (2007). De provincia a nación. Historia do galeguismo político. Vigo: Edicións Xerais de Galicia.

Carballo Calero, Ricardo (1930a). Da Universidade Galega, Unamuno, os estudantes e a Galiza. Nós. Suplemento, xx, 13-16. (Reproducido en Carballo 1987, 101-103).

Carballo Calero, Ricardo (1930b). Discurso leído por el señor Don Ricardo Carballo Calero, alumno de la Facultad de Derecho de la Universidad de Santiago de Compostela en la apertura del curso de 1930 a 1931. Santiago: [s.n.]. (Reproducido en Carballo 1987, 87-94). 
Carballo Calero, Ricardo (1931). La Fuerza pública en la Universidad de Santiago: datos y documentos. [Santiago de Compostela]: Federación Universitaria Escolar Gallega. (Reproducido en Carballo 1987, 17-83).

Carballo Calero, Ricardo (1934a). Xa somos ezquerda. A Nosa Terra, 323, 1.

Carballo Calero, Ricardo (1934b). A xeneración de Risco. Nós, 131-132, 182-184.

Carballo Calero, Ricardo (1935a). Cousas de Cataluña. A Nosa Terra, 353, 1.

Carballo Calero, Ricardo (1935b). Perante a Asambreia. A Nosa Terra, 361, 1.

Carballo Calero, Ricardo (1987). La Fuerza pública en la Universidad de Santiago y otros escritos escolares. Sada: Ediciós do Castro.

Cores Trasmonte, Baldomero (1998). O Estatuto de Autonomía de Galicia (19321936). Os documentos oficiais. Santiago de Compostela: FOESGA.

Fernán-Vello, Miguel A. e Pillado Mayor, Francisco (1986). Conversas en Compostela con Carballo Calero. Barcelona: Sotelo Blanco.

IF = Irmandades da Fala (1918). Ao pobo galego. Manifesto da Asambleia Nazonalista de Lugo. 18 de novembro, 1 p. Lugo: Irmandades da Fala.

PG = Partido Galeguista (1931). Decraración de principios. Programa de acción 1931-1932. Decembro de 1931, 4 pp. [s.1.]: Partido Galeguista.

PG = Partido Galeguista (1932). Segunda Asambreia do Partido Galeguista. Propostas que fai o Consello do Partido. Decembro de 1932, 4 pp. [s.1.]: Partido Galeguista.

PG $=$ Partido Galeguista (1933). Aos escolares. Aos universitarios. Aos galegos. Manifesto, 2 pp. Santiago: Imp. Nós. (Reproducido en El Pueblo Gallego 13/ III/1933 e en Carballo 1987, 105-112). [Redactado por Carballo Calero e asinado tamén por outros vinte e catro estudantes].

PG = Partido Galeguista (1935). Manifesto da IV Asambreia. O Partido Galeguista á opinión de Galicia. Abril de 1935, 2 pp. Pontevedra: (Imp. La Popular).

Risco, Vicente (1920). Teoría do nacionalismo galego. Ourense: (Imp. La Región).

Risco, Vicente (1930). El problema político de Galicia. Madrid: Cía Iberoamericana.

SEG = Seminario de Estudos Galegos (1931a). Anteproyeito de Estatuto de Galicia / elaborado pol-a Seizón de Ciencias Sociaes, Jurídicas i-Económicas do Seminario de Estudos Galegos, pra presentar na Asambreia galeguista da Cruña. Santiago: (Imp. Paredes).

SEG = Seminario de Estudos Galegos (1931b). Exposizón presentada pol-a poñenza encarregada de redactar o Anteproyeito de Estatuto da Galiza. Pontevedra: Casa Antúnez. [Seminario de Estudos Galegos, Seizón de Cencias Sociás, Políticas i-Económicas].

Vilas Nogueira, Xosé (1975). O Estatuto Galego. A Cruña: Ed. do Rueiro. 